\title{
PENGARUH PENAMBAHAN KARET ALAM CAIR TERHADAP SIFAT TERMAL POLYBLEND ELASTOMER TERMOPLASTIK
}

\section{(EFFECT OF LIQUID NATURAL RUBBER ADDITION ON THERMAL PROPERTIES OF ELASTOMER THERMOPLASTIC POLYBLEND)}

\author{
Sugik S. , Sudirman, Aloma K.K., Deswita dan Saeful Y. \\ Pusat Teknologi Bahan Industri Nuklir (PTBIN) - BATAN \\ Kawasan Puspiptek, Serpong, Tangerang 15314 \\ Email : sugik@batan.go.id
}

\begin{abstract}
ABSTRAK
Analisis perubahan sifat termal polipaduan elastomer termoplastik-polietilen atau elastomer termoplastikpolipropilen akibat penambahan Karet Alam Cair (Liquid Natural Rubberl LNR) telah dilakukan dengan teknik Simultaneous Thermal Analyzer (STA). Polipaduan LNR-polietilen dan LNR-polipropilen dilakukan dengan teknik blending dalam laboplastomill dengan variasi fraksi berat $L N R$ sebesar 3 \%berat, 5 \%berat dan 7 \%berat. Hasil karakterisasi dengan STA menunjukkan bahwa penambahan LNR 5 \%berat pada polipaduan elastomer termoplastik-polietilen (ETP-PE) meningkatkan suhu puncak pelelehan dari $\pm 140{ }^{\circ} \mathrm{C}$ menjadi $\pm 164,1{ }^{\circ} \mathrm{C}$, dan suhu mulai terjadinya dekomposisi meningkat dari $\pm 359{ }^{\circ} \mathrm{C}$ tanpa $L N R$ menjadi $\pm 385^{\circ} \mathrm{C}$. Sedangkan polipaduan elastomer termoplastik-polipropilen meningkatkan suhu puncak pelelehan dari $\pm 170,4{ }^{\circ} \mathrm{C}$ menjadi $\pm 178,5{ }^{\circ} \mathrm{C}$ dan suhu mulai terjadinya dekomposisi meningkat dari $\pm 370,5{ }^{\circ} \mathrm{C}$ tanpa $L N R$ menjadi $\pm 389,8{ }^{\circ} \mathrm{C}$ setelah penambahan LNR 3 \%berat.
\end{abstract}

Kata kunci : Sifat termal, Polipaduan, Elastomer termoplastik, Polipropilen, Polietilen

\begin{abstract}
Analysis and characterization of thermal properties changes of elastomer thermoplastic-polyetilene or polypropylene polyblend before and after Liquid Natural Rubber (LNR) added by Simultaneous Thermal Analyzer (STA) has been done. Blending of LNR-polyethylene and LNR-polypropylene polyblend with different mass fraction of LNR (3 \%wt, $5 \% w t$ and $7 \% w t)$ was done in laboplastomill. Characterization results by simultaneous thermal analyzer showed that addition of LNR $5 \%$ wt on ETP-polyethylene polyblend increased the melting point of polyblend from $\pm 140{ }^{\circ} \mathrm{C}$ to $\pm 164.1{ }^{\circ} \mathrm{C}$, and initial decomposition temperature increased from $\pm 359{ }^{\circ} \mathrm{C}$ to \pm $385^{\circ} \mathrm{C}$. Meanwhile ETP-polypropylene polyblend increased the melting point of polyblend from $\pm 170.4{ }^{\circ} \mathrm{C}$ to \pm $178.5{ }^{\circ} \mathrm{C}$, and initial decomposition temperature increased from $\pm 359^{\circ} \mathrm{C}$ to $\pm 385^{\circ} \mathrm{C}$ after $3 \%$ LNR added.
\end{abstract}

Key words : Thermal properties, Polyblend, Elastomer thermoplastic, Polypropylene, Polyetilene

\section{PENDAHULUAN}

Elastomer

termoplastik

(ETP)

merupakan salah satu jenis polimer plastik yang memiliki sifat elastis dan termoplastik serta paling banyak dikembangkan. Sebagai bahan baku pembuatan ETP adalah karet alam. Indonesia merupakan salah satu penghasil karet alam terbesar dengan produksi sekitar 1,4 juta ton per tahun sehingga ETP sangat sesuai dikembangkan di Indonesia untuk meningkatkan nilai tambah karet alam (Deswita dkk, 2006; Franta, 1995).
ETP memiliki sifat fisik yang baik dan dapat didaur ulang serta proses pembuatan lebih sederhana dibandingkan jenis polimer lain karena tidak memerlukan crosslink agent (Marechal, 2005; Hasyim et.al., 2002). Penggunaan ETP telah berkembang pesat sebagai bahan utama pada industri mobil, alat rumah tangga, pesawat dan senjata (Liu, 2000; Franta, 1995).

ETP mempunyai kelemahan seperti tidak Stabil terhadap suhu tinggi dan sifat fisik 
yang lemah jika dibandingkan dengan material plastik yang lain seperti epoksi, teflon dan lainlainnya (Shonaiku, 1999). Untuk mengatasi kelemahan tersebut serta meningkatkan kualitas ETP maka diperlukan adanya penambahan suatu bahan compatibilizer. Compatibilizer berfungsi untuk menyatukan dua polimer yang memiliki sifat berbeda menjadi polipaduan (Deanin, 1998). Masalah yang terjadi dalam polipaduan adalah pencampuran antara komponen-komponennya tidak sempurna sehingga menyebabkan tarikan fisik pada batas fasanya melemah dan dapat menimbulkan pemisahan fasa serta pada tekanan tertentu dapat menurunkan sifat-sifat mekanik (Shonaike, 1999).

Untuk memperbaiki kompatibilitas antara fasa-fasa yang tak dapat bercampur diperlukan bahan compatibilizer ke dalam paduan untuk memperbaiki adhesi antar fasa (Utracti, 2002). Penambahan suatu bahan compatibilizer dapat meningkatkan homogenitas dan sifat fisik serta mekanik polipaduan sehingga dapat dihasilkan polipaduan dengan sifat fisik dan termal yang lebih baik (Franta, 1995; Utracti, 2002; Fayt et.al., tt). Pada penelitian ini digunakan karet alam cair (LNR) sebagai compatibilizer dengan dua polimer jenis Polipropilen (PP) dan Polietilen (PE) yang memiliki sifat mekanik berbeda. Diharapkan dapat menghasilkan material polipaduan yang mempunyai ketahanan termal dan sifat mekanik yang berbeda pula.

Untuk mengetahui sifat termal yaitu suhu pelelehan dan suhu dekomposisi dari suatu polipaduan maka dilakukan karakterisasi termal terhadap hasil proses blending pengaruh penambahan LNR sebagai compatibilizer pada sintesa polipaduan ETP dengan PE dan ETP dengan PP menggunakan alat Simultaneous Thermal Analyzer (STA).

\section{BAHAN DAN METODE}

\section{Bahan}

Bahan-bahan penelitian adalah polietilen, polipropilen, elastomer termoplastik, dan LNR (Karet Alam Cair). Peralatan yang digunakan terdiri dari Seperangkat alat blending HAAKE - RHEOMIX 3000/3010, neraca massa Sartorius, piknometer dan Alat (STA).

\section{Metode}

Proses pembuatan polipaduan dilakukan dengan cara yaitu setiap bahan yang telah ditimbang tersebut diatas dicampur dan ditambah dengan karet alam cair $(L N R)$ dengan variasi $L N R \quad 0$ \%berat hingga 7 \%berat dan pembanding ETP-PE atau ETP-PP sebesar $100 \mathrm{~g}$ hingga $150 \mathrm{~g}$ kemudian dilakukan proses blending dengan dilakukan pengaturan suhu pemanasan terlebih dahulu, untuk proses blending menggunakan bahan PE suhu yang digunakan adalah $180{ }^{\circ} \mathrm{C}$ sedangkan untuk PP adalah $220{ }^{\circ} \mathrm{C}$. selama 10 menit. Kemudian suhu dan waktu di-setting, motor dinyalakan dengan kecepatan putaran $30 \mathrm{rpm}$. Setelah motor berputar, sampel dimasukkan secara bertahap dan ditekan agar mudah masuk ke wadah sampel dalam peralatan HAAKE tersebut.

Hasil proses blending selanjutnya dikarakterisasi termalnya menggunakan alat Simultaneous Thermal Analyzer (STA) dengan kecepatan pemanasan $10{ }^{\circ} \mathrm{C}$ permenit untuk mengetahui suhu meleleh dan suhu dekomposisinya.

\section{HASIL DAN PEMBAHASAN}

Analisis termal merupakan metode analisis dengan menggunakan parameter fisik sebagai fungsi suhu. Pada analisis termal ini ditentukan titik leleh dengan Differential Thermal Anaysis (DTA) dan suhu dekomposisi dengan Thermo Gravimetric Analysis (TGA).

Titik leleh menggambarkan perubahan fasa dari padat menjadi cair tanpa mengalami perubahan massa sedangkan suhu dekomposisi menggambarkan suhu yang diperlukan untuk membakar habis material polimer disertai dengan perubahan massa.

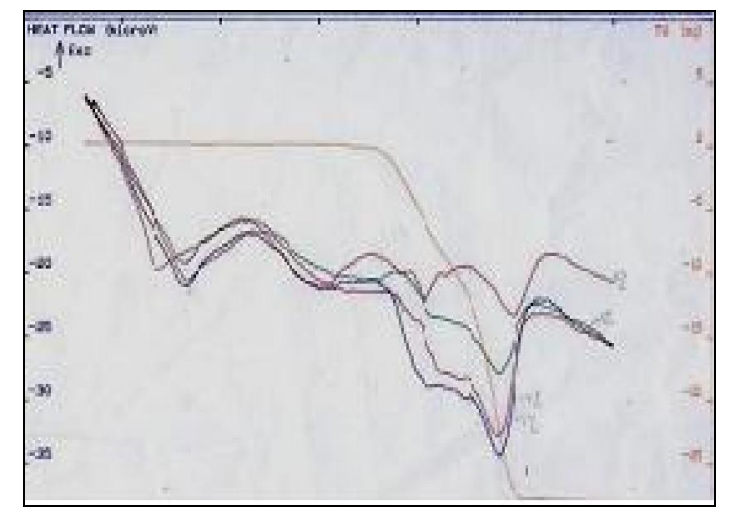

Gambar 1. Termogram DTA polipaduan ETP-PE dengan variasi $L N R$ 


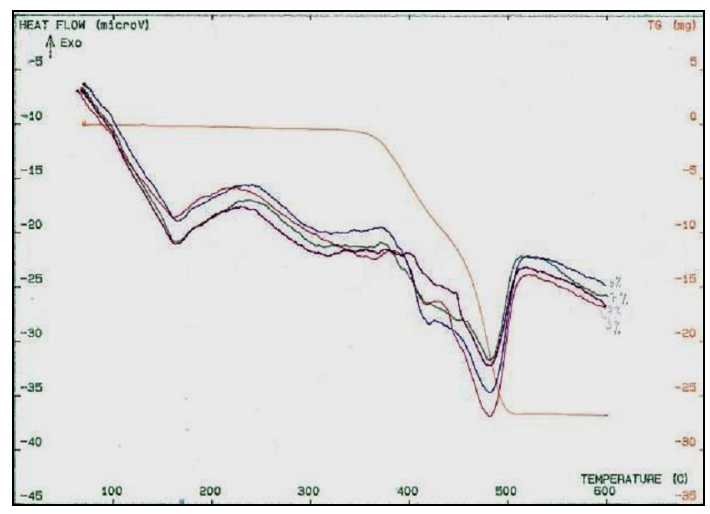

Gambar 2. Termogram DTA polipaduan ETP-PP dengan variasi \%berat $L N R$

Hasil analisis termal dari Gambar 1 dan Gambar 2 dapat diperoleh informasi bahwa pengaruh termal terhadap bahan memberikan perubahan secara fisika dan kimia. Perubahan secara fisika ditunjukkan oleh puncak dari kurva endotermis yang dimulai dengan terjadinya pelelehan bahan pada suhu diantara $90{ }^{\circ} \mathrm{C}$ hingga $180{ }^{\circ} \mathrm{C}$ kemudian bahan mencair pada kisaran suhu $180{ }^{\circ} \mathrm{C}$ hingga $360{ }^{\circ} \mathrm{C}$ selanjutnya diatas suhu tersebut sampai dengan $500{ }^{\circ} \mathrm{C}$ akan terjadi perubahan struktur kimianya yaitu bahan mulai ter-dekomposisi.

Dari Gambar 1 dan Gambar 2 dapat dilihat terdapat dua puncak endotermis yang berbeda. Puncak pertama memberikan informasi mengenai titik leleh dari bahan sedangkan puncak kedua memberikan informasi mengenai suhu dekomposisi. Penambahan LNR baik terhadap polipaduan ETP-PE atau polipaduan ETP-PP menunjukkan adanya pengaruh terhadap karakter termal bahan, baik suhu pelelehan maupun suhu dekomposisi. Jika dilihat puncak pelelehan polipaduan ETP-PE tanpa $L N R$ terjadi pada suhu $\pm 140{ }^{\circ} \mathrm{C}$ maka dengan penambahan $L N R$ puncak pelelehan mengalami perbedaan yaitu terjadi pada suhu $\pm 164,1{ }^{\circ} \mathrm{C}$. Hal tersebut menunjukkan bahwa dengan penambahan $L N R$ dapat meningkatkan ketahanan termal polipaduan ETP-PE sampai $\pm 24{ }^{\circ} \mathrm{C}$ (Gambar 1).

Pengaruh persentase jumlah LNR yang ditambahkan mengakibatkan puncak pelelehan-nya juga mengalami peningkatan walaupun cukup kecil yaitu dibawah $5{ }^{\circ} \mathrm{C}$. Gambar 1 juga menunjukkan adanya pergeseran puncak-puncak pelelehan ETP-PE pada $L N R 3 \%$ berat adalah $\pm 161,5^{\circ} \mathrm{C}, L N R$ 5 \%berat adalah $\pm 164,1{ }^{\circ} \mathrm{C}$ ataupun $L N R$ 7 \%berat adalah $\pm 162,7{ }^{\circ} \mathrm{C}$, sedangkan untuk polipaduan ETP-PP tanpa $L N R$ pelelehan terjadi pada suhu $\pm 170,4{ }^{\circ} \mathrm{C}$, untuk penambahan $L N R$ 3 \%berat puncak pelelehan terjadi kenaikan puncak pelelehan pada suhu $\pm 178,5{ }^{\circ} \mathrm{C}$ mengalami perbedaan puncak pelelehan kurang dari $\pm 8{ }^{\circ} \mathrm{C}$. Puncak pelelehan ETP-PP pada LNR $3 \%$ berat terjadi pada suhu $\pm 178,5{ }^{\circ} \mathrm{C}$, LNR $5 \%$ berat adalah $\pm 176.2{ }^{\circ} \mathrm{C}$ ataupun $L N R$ $7 \%$ berat adalah $\pm 177,1{ }^{\circ} \mathrm{C}$. Hal tersebut dapat terlihat pada Gambar 2

Dari Gambar 1 dan Gambar 2 diperoleh suhu dekomposisi masing-masing polipaduan ditunjukkan oleh kurva endotermis yang terjadi antara suhu $\pm 360{ }^{\circ} \mathrm{C}$ sampai $\pm 503{ }^{\circ} \mathrm{C}$ dimana pada suhu tersebut material polipaduan telah terurai menjadi penyusun-penyusunnya yang disertai pula dengan penurunan berat. Pada suhu diatas $503,4{ }^{\circ} \mathrm{C}$ beratnya menjadi tetap dan yang tersisa adalah unsur karbon.

$$
\text { Pada polipaduan PE-ETP-LNR }
$$

0\%berat dari Gambar 1 tersebut diatas polipaduan mulai terdekomposisi pada suhu $359,7{ }^{\circ} \mathrm{C}$ sedangkan puncaknya terjadi pada $504,5{ }^{\circ} \mathrm{C}$. Penambahan LNR 3 \% berat dan $5 \%$ berat mulai terdekomposisi pada suhu $\pm 375^{\circ} \mathrm{C}$ dan $\pm 385^{\circ} \mathrm{C}$ untuk penambahan $L N R$ 7 \%berat mulai terdekomposisi pada suhu $\pm 370{ }^{\circ} \mathrm{C}$. Hal tersebut menunjukkan bahwa penambahan $L N R$ dapat meningkatkan suhu dekomposisi. Pada Gambar 1 terlihat juga bahwa pada penambahan LNR 7 \% berat mengalami penurunan suhu dekomposisinya dibandingkan LNR 3 \%berat dan 5 \%berat. Hal tersebut menunjukkan bahwa penambahan $L N R$ yang optimum sampai 5 \%berat dapat meningkatkan sifat termal polipaduan ETP dengan PE.

Pada polipaduan ETP-PP-LNR 0 \%berat seperti terlihat pada Gambar 2 menunjukkan bahwa polipaduan mulai terjadi dekomposisi pada suhu $\pm 370,5{ }^{\circ} \mathrm{C}$ sedangkan puncaknya terjadi pada $\pm 491,9{ }^{\circ} \mathrm{C}$. Penambahan LNR 3 \%berat dan 5 \%berat pada polipaduan ETP dengan PP mulai terdekomposisi pada suhu $\pm 389,8{ }^{\circ} \mathrm{C}$ dan $\pm 381,3{ }^{\circ} \mathrm{C}$ sedangkan pada penambahan $L N R$ 7 \%berat mulai terdekomposisi pada suhu $\pm 386,8^{\circ} \mathrm{C}$

Hal tersebut menunjukkan bahwa penambahan LNR sampai dengan 3 \%berat dapat meningkatkan suhu dekomposisinya sedangkan pada penambahan LNR 5 \% berat dan 7 \%berat mengalami penurunan suhu dekomposisinya jika dibandingkan dengan penambahan sejumlah $L N R 3$ \% berat. 
Tabel 1. Termal jenis polipaduan ETP-PE dan ETPPP dengan variasi \%berat $L N R$

\begin{tabular}{|c|c|c|c|}
\hline \multirow{2}{*}{$\begin{array}{l}\text { Jenis } \\
\text { Polipaduan }\end{array}$} & \multirow{2}{*}{$\begin{array}{c}\text { Pelelehan } \\
\text { Puncak } \\
\left( \pm{ }^{0} \mathrm{C}\right)\end{array}$} & \multicolumn{2}{|c|}{ Dekomposisi } \\
\hline & & $\begin{array}{l}\text { Awal } \\
\left( \pm{ }^{0} \mathrm{C}\right)\end{array}$ & $\begin{array}{c}\text { Puncak } \\
\left( \pm{ }^{\circ} \mathrm{C}\right)\end{array}$ \\
\hline $\begin{array}{c}\text { ETP- PE - } \\
0 \% \text { LNR }\end{array}$ & 140 & 359,7 & 504,5 \\
\hline $\begin{array}{c}\text { ETP- PE - } \\
3 \% \text { LNR }\end{array}$ & 161,5 & 375 & 495,4 \\
\hline $\begin{array}{c}\text { ETP- PE - } \\
5 \% \text { LNR }\end{array}$ & 164,1 & 385 & 498,6 \\
\hline $\begin{array}{c}\text { ETP- PE - } \\
7 \% \text { LNR }\end{array}$ & 162,7 & 370 & 494,7 \\
\hline $\begin{array}{c}\text { ETP- PP - } \\
0 \% \text { LNR }\end{array}$ & 170,4 & 370,5 & 491,9 \\
\hline $\begin{array}{c}\text { ETP- PP - } \\
3 \% \text { LNR }\end{array}$ & 178,5 & 389,8 & 490,7 \\
\hline $\begin{array}{c}\text { ETP- PP - } \\
5 \% \text { LNR }\end{array}$ & 176,2 & 381,3 & 489,6 \\
\hline $\begin{array}{c}\text { ETP- PP - } \\
7 \% \text { LNR }\end{array}$ & 177,1 & 386,8 & 490,2 \\
\hline
\end{tabular}

Dari Tabel 1 termal jenis polipaduan ETP-PE dan ETP-PP dengan variasi \%berat $L N R$ hasilnya terlihat bahwa penambahan $L N R$ dapat berpengaruh pada suhu pelelehan maupun suhu dekomposisi.

Tabel 1 menunjukkan bahwa penambahan $L N R$ sampai dengan 5 \%berat pada polipaduan ETP-PE dapat meningkatkan suhu pelelehan dan suhu awal dekomposisinya jika dibandingkan tanpa LNR. Hal tersebut mengindikasikan bahwa pengaruh $L N R$ sebagai compatibilizer dapat meningkatkan sifat termal dari polipaduan ETP-PE.

Selain itu, pengaruh penambahan $L N R$ sampai 3 \%berat pada polipaduan ETP-PP dapat pula meningkatkan suhu pelelehan dan suhu dekomposisinya. Struktur molekul PE dan PP yang berbeda mengakibatkan pengaruh suhu pelelehan dan suhu dekomposisinya mengalami perbedaan pula terhadap hasil polipaduannya. Dari Tabel 1 ditunjukkan bahwa pengaruh $L N R$ terhadap polipaduan ETP-PE lebih baik dibandingkan dengan polipaduan ETP-PP jika ditinjau dari peningkatan suhu pelelehan dan suhu dekomposisinya.

\section{KESIMPULAN}

Karet alam cair (Liquid Natural Rubberl LNR) sebagai bahan compatibilizer dapat meningkatkan sifat termal yaitu sifat pelelehan dan sifat dekomposisi polipaduan ETP-PE dan ETP-PP. Kondisi optimum ETP-PE dicapai pada komposisi $L N R 5 \%$ berat sedangkan untuk ETP-PP dicapai pada komposisi LNR 3 \%berat. Pengaruh LNR pada polipaduan ETP-PE lebih baik dibandingkan polipaduan ETP-PP.

\section{DAFTAR PUSTAKA}

[1] Ancker, Fred H., Warren N.J. Method of Preparing Mixtures of Incompatible Hydrocarbon Polymers. U.S. Patent No. 487311. 10 October 1989

[2] Azanam Hasyim, S.K. Ong, R.S. Jessy. 2002. General Review of Recent Developments on Chemical Modification of NR. Natural Rubber Journal (28).

[3] Bilmeyer,F.W. 1984. Textbook of Polymer Science. $3^{\text {rd }}$ ed. John Wiley \& Sons Inc. New York.

[4] Deswita, Sudirman. 2006. Pengembangan Elastomer Termoplastik Berbasis Karet Alam dengan Polietilen dan Polipropilen untuk Bahan Industri. Jurnal Sains Materi Indonesia. No. 5 Vol. 8.

[5] Fayt, Hadjiandreau, and Teyssie. Miscible and Immiscible Polymer Blends. Journal Polymer Science. $23^{\text {rd }}$ ed. p.337.

[6] Franta, I. 1995. Elastomer and Rubber Compounding Material. Studies in Polymer Science. Elsevier Publisher.

[7] Justin Hamilton. 2000. Thermoplastic Elastomer: New Development. Manufacturing Journal. p. 355.

[8] Kozlowska A, Ukielski R, Piatek M. 2006. Thermal Properties of Multiblock Oligoamide Soft Block Derived From Dimerized Fatty Acid. Journal of Thermal Analysis and Colorimetry. Vol. 28. No. 2. p. $349-353$ (5).

[9] Liu, H.S. 2000. Compatibilization Approaches for Recycled Rubber/ Thermoplastic Blending. Society for Advancement of Materials and Process Engineering Journal. $32^{\text {nd }}$ ISTC. Boston. 5 - 9 November.

[10] Marechal, E. 2005. Creation and Development of Thermoplastic Elastomer, and Their Position Among Organic Materials. Handbook of Condensation Thermoplastic Elastomers $1^{\text {st }}$ ed, p.1-31. John Wiley. 
[11] Rudolph Deanin.1998. Compatibilization of Polymer Blends. University of Massachutsetts. USA.

[12] Shonaike, G.O. 1999. Mechanical and Thermal Properties of Copolymer (Styrene/ Acrylonitrile) Compatibilized Nylon Thermoplastic Elastomer Blends. Journal Plastic Rubber and Composites Vol. 28 No. 10. p.494499.

[13] Sivaraman P, N. R. Manoj, S. Barman, L. Chandrasekhar, V. S. Mishra, A. B. Samui and B. C. Chakraborty. 2004. Thermal and Rheological Studies: Thermoplastic Copolymer Ester Elastomer Toughened Polycarbonate Blends. Polymer Testing Vol. 23. 6 September. p. 645-649.

[14] Utracti, L. A. 2002. Compatibilization of Polymer Blends. The Canadian Journal of Chemical Engineering Vol. 80. p.100 